\title{
BGH-Rechtsprechung: Nachträgliche Sicherungsverwahrung ist lediglich nach genauer Prüfung erlaubt
}

\author{
STGB § 66b Abs.1; StPO § 275a Abs. 4
}

Gönke Jacobsen

1. Die Verweigerung oder der Abbruch einer Therapie können zwar grundsätzlich neue Tatsachen sein, die erst nach der Verurteilung und vor Ende des Vollzuges erkennbar werden und auf eine erhebliche Gefährlichkeit des Verurteilten für die Allgemeinheit hinweisen, reichen aber für sich allein nicht aus, eine nachträgliche Sicherungsverwahrung anzuordnen.

2. Die Prüfung des Merkmals des Hanges zu erheblichen Straftaten ( $\$ 66$ Abs. 1 Nr. 3 StGB) ist auch im Rahmen der Anordnung einer nachträglichen Sicherungsverwahrung nicht entbehrlich.

3. Aus § 275a Abs. 4 Satz 1 StPO ergibt sich nicht zwingend, dass mit der Begutachtung jeweils zwei Fachärzte mit psychiatrischer Ausbildung und Erfahrung beauftragt werden müssen.

BGH, Urt. v. 11.5.2005 - 1 StR 37/05 (LG Bayreuth)

Die Urteilsgründe sind zu finden in NJW 2005, 2022 ff.; StV 2005, 388 ff.; StraFo 2005, S. 300 ff. mit Anmerkung Böhm.

$\S 66$ b ist im Jahre 2005 nach der 2002 eingefügten Variante der im erkennenden Urteil vorbehaltenen Sicherungsverwahrung neu eingefügt worden, um Grenzfälle zu erfassen. In der Literatur wurde befürchtet, dass es in der Rechtspraxis zu einem Sicherungsstrafrecht kommen könnte. Diese Befürchtung jedenfalls hat die ständige Rechtsprechung der Vollstreckungsgerichte, die nun durch den BGH bestätigt wird, ausgeräumt.

Der 1. Strafsenat des BGH hat mit diesem Urteil zur nachträglichen Sicherungsverwahrung klargestellt, dass die Entscheidung über die Anordnung der Sicherungsverwahrung nach der Vollstreckung der Freiheitsstrafe den gleichen Anforderungen unterliegt wie im Erkenntnisverfahren. Die nachträgliche Sicherungsverwahrung ist somit kein Instrument zweiter Güte und das Tatgericht kann eventuelle Fehler nicht nachträglich ausgleichen. Der BGH betont, dass neben den unmittelbaren Voraussetzungen des $\S 66 \mathrm{~b}$ StGB erst die Gesamtwürdigung der Täterpersönlichkeit einschließlich der entscheidungserheblichen Daten aus der Lebens- und Kriminalitätsgeschichte des Betroffenen die Anordnung der Maßregel erlauben. Damit ist das Ziel der Einfügung der nachträglichen Sicherungsverwahrung in das Sanktionenrecht, nämlich ein restriktiv zu handhabendes Instrument für Ausnahmefälle zu schaffen, von der Rechtsprechung umgesetzt worden.

Diese Begrenzung konterkariert allerdings die nicht $\mathrm{zu}$ stoppende Welle von Forderungen nach lebenslangem Wegsperren von sexualdelinquenten Ersttätern. Die Massenmedien berichten so, als könne man keine Taten mit sexuell motiviertem Hintergrund mehr akzeptieren, sondern das Ideal einer hundertprozentigen Sicherheit anstreben.

Exemplarisch für diese Haltung steht die Reaktion auf den Tod des Mädchens Carolin aus der Nähe von Rostock. Zur Erinnerung: Am 15. Juli ist die 16-jährige Schülerin verschwunden, am 18. Juli wurde ihre Leiche in der Rostocker Heide gefunden. Laut Medienberichten hat ein Spürhund die Ermittler zu dem Tatverdächtigen geführt. Die Auswertung von DNA-Spuren erhärtet den Verdacht, dass der Mann sich an dem Mädchen sexuell vergangen und es anschließend mit massiver Gewalteinwirkung auf den Kopf getötet hat. Bei dem Tatverdächtigen handelt es sich um einen 29 Jahre alten Mann aus der Region um Rostock, der am 8. Juli nach der Vollverbüßung einer siebenjährigen Haftstrafe wegen Vergewaltigung, schweren Raubes und Geiselnahme entlassen worden war.

Der »Fall Carolin« fand seinen Widerhall in allen bundesdeutschen Zeitungen mit mehrtägiger Berichterstattung über die Ermittlungserfolge von Staatsanwaltschaft und Polizei. Allen voran die Bildzeitung. Sie titelte: »Nicht schon wieder! Carolin im Wald verschwunden. Lieber Gott, laß es nicht schon wieder passiert sein! « und
"Schöne Carolin im Wald erschlagen. Festnahme! Mutmaßlicher Mörder kam erst vor wenigen Tagen aus dem Knast.", Haftbefehl! Schlug ER (scil: Foto) Carolin den Schädel ein? «, »Der mutmaßliche Mörder von Carolin ( $† 16)$. Hier grillt er mit seiner Mama.« Neben der starken Personalisierung von Täter und Opfer, an die man sich fast schon gewöhnt hat, inszeniert die Medienwelt ein Schauspiel wie "Die Schöne und das Biest «. Und wer hat Schuld?

Schnell werfen Politiker den Begriff »Justizversagen « in die Diskussion, dem ein Ruf nach härteren Gesetzen folgt. In letzter Konsequenz kann dies nur Sicherungsverwahrung für Ersttäter bedeuten. Warum das Tatgericht vor sieben Jahren keine Sicherungsverwahrung angeordnet hat, entzieht sich jeglicher Kenntnis an dieser Stelle und Spekulationen verbieten sich. Der mutmaßliche Täter wurde jedoch in einer Sozialtherapeutischen Anstalt während des Strafvollzuges behandelt. Wie das Justizministerium gegenüber der Öffentlichkeit Auskunft gegeben hat, sahen die Therapeuten kein hohes Gefährdungspotential bei dem Betroffenen. Folglich musste dieser in Freiheit gelassen werden. Damit ist das Dilemma der Fälle, wie »Carolin« einer darstellt, formuliert. Wer erst am Ende der Verbüßung der Freiheitsstrafe von Sexualstraftätern über deren Gefährlichkeit nachdenkt, muss scheitern. Vielmehr geht § 66b StGB, wie auch der BGH in dem vorgestellten Urteil bestätigt hat, davon aus, dass die Gefährlichkeit eines Straftäters sich regelmäßig schon bei der Verurteilung zeigt; ist doch der größte Anhaltspunkt dafür die begangene Tat. Aus diesem Grund ist der Platz zur Erörterung der Gefährlichkeitsprognose stets die Hauptverhandlung des Tatgerichts. Plakative Forderungen nach mehr Sicherung gehen deshalb an dem Problem vorbei. Sinnvoll ist es dagegen, über eine Erweiterung des Einsatzes von Sachverständigen zur Frage der Gefährlichkeit gemäß § 246a StPO zu diskutieren (vgl. hierzu den Beitrag in diesem Heft).

\section{Die Autorin ist Doktorandin in Kiel}

